Short Communication

\title{
Low density-microplastics detected in sheep faeces and soil: A case study from the intensive vegetable farming in Southeast Spain
}

\author{
Nicolas Beriot ${ }^{\mathrm{a}, \mathrm{b}, *}$, Joost Peek ${ }^{\mathrm{a}}$, Raul Zornoza ${ }^{\mathrm{b}}$, Violette Geissen ${ }^{\mathrm{a}}$, Esperanza Huerta Lwanga ${ }^{\mathrm{a}, \mathrm{c}}$ \\ a Soil Physics and Land Management Group, Wageningen University E Research, P.O. Box 47, 6700AA Wageningen, the Netherlands \\ b Sustainable Use, Management and Reclamation of Soil and Water Research Group, Universidad Politécnica de Cartagena, Paseo Alfonso XIII, 48,30203 Cartagena, Spain \\ c Agroecología, El Colegio de la Frontera Sur, Unidad Campeche, Campeche, Mexico
}

\section{H I G H L I G H T S}

- Microplastics were measured in soil and sheep faeces in Southeast Spain.

- All the soil samples from the farms applying plastic mulch contained microplastics.

- $92 \%$ of the faeces samples contained microplastics.

- Defecation of a sheep herd can transport $\sim 10^{6}$ microplastics.ha $^{-1} \cdot \mathrm{y}^{-1}$ to a field.

\section{G R A P H I C A L A B S T R A C T}

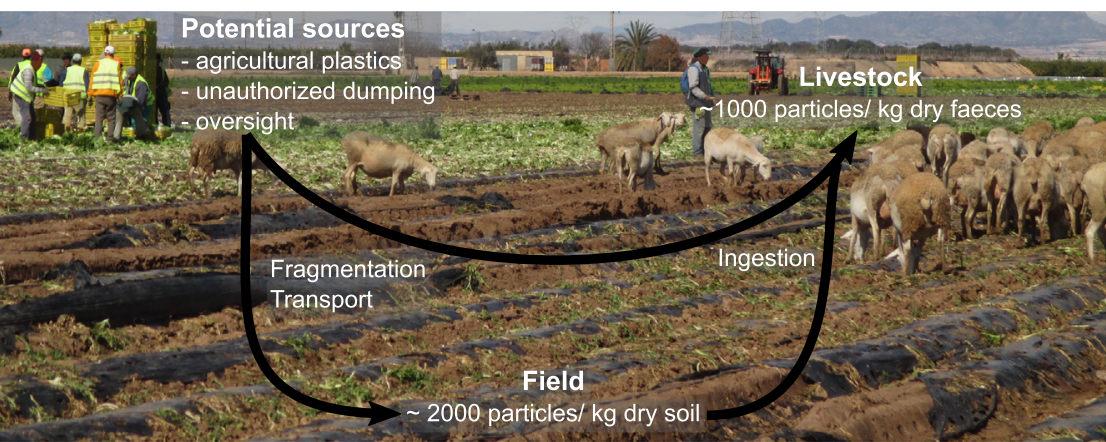

\section{A R T I C L E I N F O}

\section{Article history:}

Received 4 July 2020

Received in revised form 10 September 2020

Accepted 24 September 2020

Available online 1 October 2020

Editor: Yolanda Picó

\section{Keywords:}

Microplastics

Plastic residues

Terrestrial food chain transfer

Livestock

Sheep

\begin{abstract}
A B S T R A C T
One of the main sources of plastic pollution in agricultural fields is the plastic mulch used by farmers to improve crop production. The plastic mulch is often not removed completely from the fields after harvest. Over time, the plastic mulch that is left of the fields is broken down into smaller particles which are dispersed by the wind or runoff. In the Region of Murcia in Spain, plastic mulch is heavily used for intensive vegetable farming. After harvest, sheep are released into the fields to graze on the vegetable residues. The objective of the study was to assess the plastic contamination in agricultural soil in Spain and the ingestion of plastic by sheep. Therefore, three research questions were established: i) What is the plastic content in agricultural soils where plastic mulch is commonly used? ii) Do livestock ingest the microplastics found in the soil? iii) How much plastic could be transported by the livestock? To answer these questions, we sampled top soils $(0-10 \mathrm{~cm})$ from 6 vegetable fields and collected sheep faeces from 5 different herds. The microplastic content was measured using density separation and visual identification. We found $\sim 2 \times 10^{3}$ particles $\cdot \mathrm{kg}^{-1}$ in the soil and $\sim 10^{3}$ particles $\cdot \mathrm{kg}^{-1}$ in the faeces. The data show that plastic particles were present in the soil and that livestock ingested them. After ingesting plastic from one field, the sheep can become a source of microplastic contamination as they graze on other farms or grasslands. The potential transport of microplastics due to a herd of 1000 sheep was estimated to be $\sim 10^{6}$ particles $\cdot \mathrm{ha}^{-1} \cdot \mathrm{y}^{-1}$. Further studies should focus on: assessing how much of the plastic found in faeces comes directly from plastic mulching, estimating the plastic degradation in the guts of sheep and understanding the potential effects of these plastic residues on the health of livestock.
\end{abstract}

(C) 2020 The Author(s). Published by Elsevier B.V. This is an open access article under the CC BY license (http:// creativecommons.org/licenses/by/4.0/).

\section{Introduction}

* Corresponding author at: Soil Physics and Land Management Group, Wageningen University \& Research, P.O. Box 47, 6700AA Wageningen, the Netherlands.

E-mail address: nicolas.beriot@wur.nl (N. Beriot).
Microplastics have been detected in many matrices and in all different environments: from oceans to remote mountains, from earthworms 
to wild birds (Wu et al., 2019). Microplastics are also present in food (Prata et al., 2020) and human stools (Schwabl et al., 2019). Plastic can be transported from one environment to another by wind and water (Horton and Dixon, 2018) and by other organisms. Microplastics entering the food chain in aquatic environments have been extensively studied (Wang et al., 2019). However, only a few studies have described the transfer of microplastics via terrestrial organisms. Earthworms were the first soil-dwelling organisms to be studied for ingesting microplastics (Huerta Lwanga et al., 2017a; Rillig et al., 2017). Huerta Lwanga et al. (2017b) demonstrated that microplastics could be transferred from the soil $\left(0.87 \pm 1.9\right.$ particles. $\left.{ }^{-1}\right)$ to earthworms $(14.8 \pm$ 28.8 particles. ${ }^{-1}$ ) and chickens in traditional Mayan home gardens in Southeast Mexico. Chae and An (2020) demonstrated the transfer of nanoplastic particles from the soil $\left(10-100 \mathrm{mg} \cdot \mathrm{kg}^{-1}\right)$ to leaves of mug beans and snails (few particles, number not reported). Microplastics are identified in many agricultural fields (Yang et al., 2020) but no studies assessed the ingestion of microplastics by grazing livestock.

Microplastics can enter agricultural fields via many ways: primary use of plastic in the fields, amendment with products contaminated with microplastics or transport from other environments (Xu et al., 2020). On one hand, plastic provides many services in agriculture and is extensively used in modern managements (Liu et al., 2014). For example plastic mulch is used for increasing soil temperature, controlling weeds, and improving water use efficiency while plastic nets are used for crop protection and plastic pipes provide irrigation. These plastics undergo degradation in the field. The degradation depends on abiotic reactions such as thermal degradation, photo-degradation, oxidation, hydrolysis and mechanical degradations (e.g. wind or ploughing) (Crawford et al., 2017). Due to the degradation of agricultural plastics, fragments of plastic may accumulate in the soil. On the other hand microplastics may enter agricultural fields through the application of biofertilizers contaminated with plastics. Indeed sewage sludge (Corradini et al., 2019b) and composts (Weithmann et al., 2018) may contain high contents of microplastics. Finally microplastics can be transported by the wind (Zhang et al., 2020) and flooding waters (Bläsing and Amelung, 2018) in and out of the soil system.

In the region of Murcia in south-eastern Spain, plastic mulch has been used to prevent evaporation in vegetable fields for more than 20 years. Although this semiarid region suffers from severe lack of water owing to a semiarid Mediterranean climate, it is nonetheless an intensively irrigated horticultural area, commonly known as the "European garden" (tr. "Huerta de Europa"). On average, two crops per year are grown in each field. Plastic mulch is used in the summer and sometimes in the winter. Due to the intensive use of plastic mulch and its incomplete removal after harvesting, many agricultural fields are contaminated with plastic debris. Moreover, some plastic bags and plastic films (used for silage or packaging) can be lost in the fields, for example, due to oversight during vegetable wrapping at mobile harvesting stations. After harvest, a common practice is to bring sheep to eat the crop residues. In Murcia, 638,000 sheep were bred in 2019 for meat production (Dirección General de Producciones y Mercados Agrarios, 2020). Most of the sheep farming relies heavily on crop residue grazing and fallow land grazing and little fodder is provided. Few sheep farms own land and grow fodder to feed the herd that stays in the sheepfold. The food residence time in a sheep's digestive system is about $35 \mathrm{~h}$ (Huston et al., 1986). Therefore, we can expect that plastic particles ingested in one field are transferred to another field when the sheep defecate. This transport is particularly relevant when a herd first grazes an agricultural field contaminated with plastic and then moves to fallow land or a natural area.

The objective of the study was to assess the microplastic pollution in an agricultural area owing to intensive management practices. We focused on the light density microplastic contamination in the lithosphere and the biosphere with two representative samples: vegetable agricultural soil samples and faeces of sheep grazing in fields where plastic mulch was used. Therefore, three research questions were established: i) What is the light density microplastic content in farm soils where plastic mulch is commonly applied? ii) Do livestock ingest microplastic? iii) How much plastic is transported by the livestock? We hypothesized that the soil would be contaminated with plastic particles coming from mulch debris and the sheep would then ingest the plastic and excrete microplastic particles in their faeces, thus contributing to the dispersion of plastic debris in the environment.

\section{Materials and methods}

\subsection{Study site}

The study was carried out in the countryside of the Murcia region (SE Spain, Fig. 1). Soil samples were collected from 6 vegetable fields where light density polyethylene plastic mulch was applied at least once per year over the last 10 years. All the fields had similar crop rotation history which included melons in summer and lettuces, broccoli and fennel in winter, among others. Some farms used plastic much twice a year to cover soil during the winter and summer crop cycles. Five different herds of sheep were selected in the same region for faecal collection. There were approximately 1000 sheep per herd. The first four herds (A, B, C, D, Fig. 1) grazed crop residues at surrounding vegetable farms, grass in fallow lands and ate additional feed at their sheepfolds. The herds A, B, C, D visited several vegetable farms and fallow lands at the vicinity of their sheepfold, depending on the available crop residues and grass. Most cattle breeders in the region do not owe land for agriculture, so they depend on neighbour farmers so their cattle can graze on the vegetable residues left on the farms after harvest. The fifth herd (E) stayed at the sheepfold all year and grazed in the fields of the sheepfold daily. The herd $\mathrm{E}$ was fed with crop residues brought to the farm and locally produced corn, hay and silage. The shepherds where interviewed about the potential consumption of plastic by the sheep.

\subsection{Sample collection}

Soil sampling was carried out after the winter harvest and before the soil preparation for the summer crop cycle in 2018. Three parcels of $\sim 0.5$ ha were selected from each vegetable farm and 3 sampling points were uniformly dispersed in each sampling parcel. Soil from the top 0-10 cm was collected for each sampling point. Fresh sheep faeces were randomly collected from each herd in the field (herd A, B, C, D) or in the sheepfold (herd E). We sampled 8-18 faecal samples for each herd.

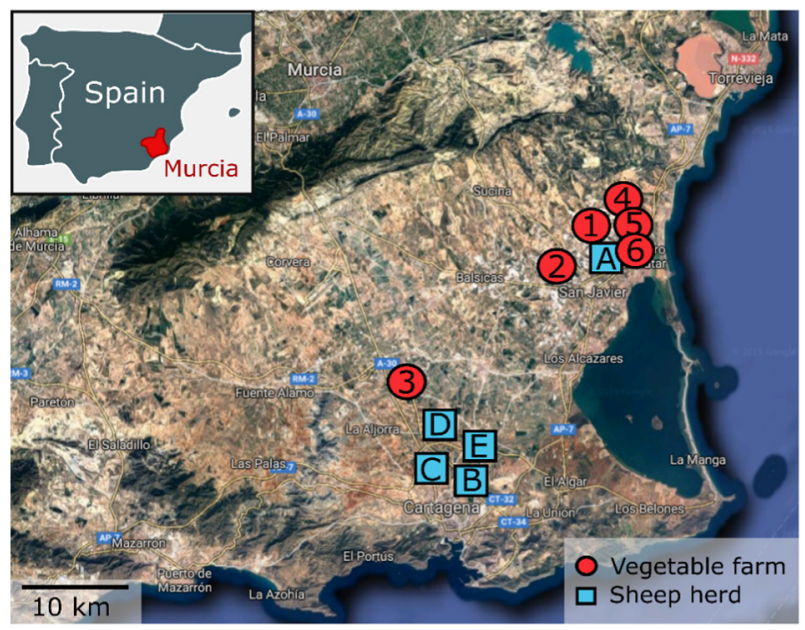

Fig. 1. Approximate locations of the 6 vegetable fields (in red circles: $1-6$ ) and the 5 sheep herds (in blue squares: A-E) in the region of Murcia (SE Spain, in order to maintain the anonymity of the owners the sites are presented approximately). 


\subsection{Microplastic extraction}

Samples were air dried and analysed to assess the presence of light density microplastics. The procedure for light density microplastic extraction and identification was adapted from Zhang et al. (2018) and Corradini et al. (2019b). Briefly, $5 \mathrm{~g}$ of dried sample were placed into a $50 \mathrm{~mL}$ tube with $30 \mathrm{~mL}$ of distilled water and shacked at $150 \mathrm{rpm}$ for $30 \mathrm{~min}$ in a platform shaker. Tubes were then centrifuged at 3000 RPM for 10 min. The supernatant was transferred onto a Whatman No. 42 filter paper. Tubes were refiled with distilled water, shacked again and put in an ultrasonic bath for 10 min to further break down soil aggregates. The samples were centrifuged again, and the supernatants were poured onto the same filters. The filters were then air dried for $24 \mathrm{~h}$ before microplastic identification and quantification were carried out. Additionally, six blanks were performed without samples along the analysis (every $\sim 20$ samples) to detect an eventual contamination during the extraction and identification procedure.

\subsection{Microplastic identification}

All materials present on a filter were brushed carefully onto a glass plate and gathered in the centre of the plate while trying to avoid superposition of particles. A stereo microscope (ZEISS Stemi 508) equipped with a digital camera (CMEX-18 PRO) was used to take a picture of the particles. Pictures were taken with $\mathrm{x} 6$ magnification. The glass plate was then put onto a hot plate at $130^{\circ} \mathrm{C}$ for 10 s and a second picture was taken. The plastic particles were then identified among other soil particles and organic matter by looking at their shape, colour, brightness and response to heat (Zhang et al., 2018).

\subsection{Calculations}

The number of plastic particles per sample was presented in terms of number of microplastics per kilogram of dry matter ( particles. $\mathrm{kg}^{-1}$ ) and displayed with the function ggplot of R version 3.6.1 for the two different matrices and for the different fields and herds. The order of magnitude for microplastics was estimated as the smallest power of 10 used to represent that number. We performed a Shapiro-Wilk's test for the soil and faeces samples independently with the R function shapiro.test.

The number of microplastics potentially transported by a herd of 1000 sheep grazing in 1 ha of land in one day $\left(M P_{\text {herd }}\right.$ in particles $\left.\cdot h a^{-1} \cdot d^{-1}\right)$ was calculated using Eq. (1):

$\begin{aligned} M P_{\text {herd }}= & M P_{\text {Faeces }} \times \text { Faeces }_{\text {animal }} \times \text { Defecation }_{\text {Field }} \times \text { Animal }_{\text {herd }} \\ & \times \text { Herd }_{\text {Field }}\end{aligned}$

where $M P_{\text {Faeces }}$ is the number of microplastics per $\mathrm{kg}$ of fresh faeces ( particles $\cdot \mathrm{kg}^{-1}$ ), Faeces animal $_{\text {is }}$ is the faecal production per sheep per day ( $\sim 1 \mathrm{~kg}$ per sheep and per day according to Ogejo et al. (2010)), Defecation $_{\text {Field }}$ is the sheep defecation percentage that occurs in the field ( $36 \%$ of $1 \mathrm{~kg}$ per sheep, according to Taylor et al. (1987)), Animal ${ }_{\text {herd }}$ is the number of sheep per herd ( 1000 per herd; Agudo et al. (2010) observed an optimal production for a herd size between 1200 and 2000 heads) and Herd Field $_{\text {is }}$ the surface grazed by the herd in one day ( 1 ha for an herd of 1000 sheep; (Rakkar and Blanco-Canqui, 2018)). Eq. (1) is suitable for other grazing animals with adapted values. The number of microplastics potentially transported $\left(M P_{\text {herd }}\right)$ was extrapolated to a year by considering that each field was grazed two times (winter crop and summer crop) per year.

\section{Results and discussion}

\subsection{Microplastics in agricultural soils}

Microplastics were found in all soil samples (Fig. 2). The distribution of microplastics in the dry soil followed a normal distribution

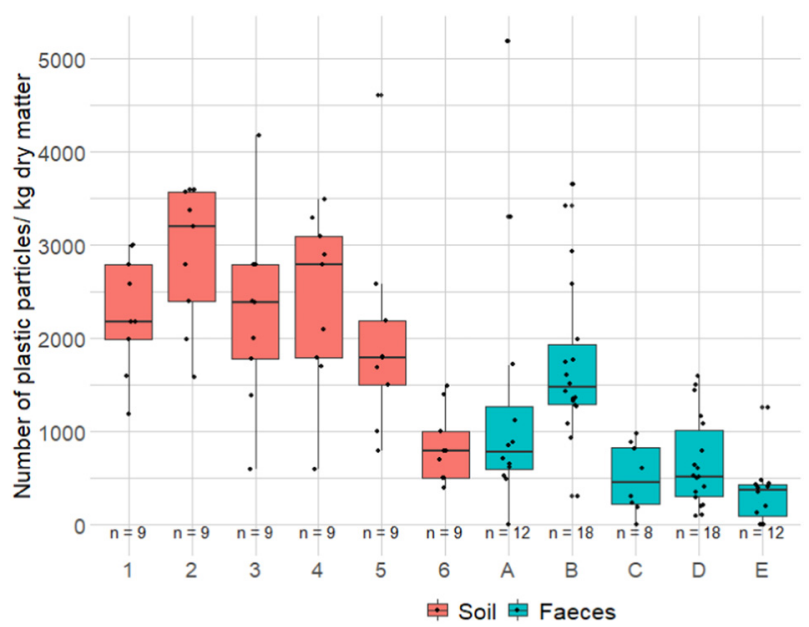

Fig. 2. Microplastic content in agricultural soil (in red: 1-6) and in sheep faeces (in blue: A-E) per field and herd. The dots represent individual measurements ( $\mathrm{n}=$ number of replicates).

( $p$-value $=0.33$ ). The average content of microplastics in dry soil was $2116 \pm 1024$ particles $\mathrm{kg}^{-1}$. The amount of microplastics found in these soils is comparable to the amount of microplastics found in other agricultural soils. van den Berg et al. (2020) reported an average of light density microplastic content of $2130 \pm 950$ particles $\cdot \mathrm{kg}^{-1}$ in agricultural fields used to grow cereals in Eastern Spain. Zhang and Liu (2018) reported higher microplastic contents, ranging from 7100 particles $\cdot \mathrm{kg}^{-1}$ to 42,960 particles $\cdot \mathrm{kg}^{-1}$, in arable soils near the Chai river valley (southwestern China). There is not much information concerning the effect of plastics on the soil function and the processes remain unclear so it is difficult to foresee the consequences of this plastic pollution on soil quality and long-term land productivity. For example, researchers have reported that plastic debris can be detrimental to plant growth (Qi et al., 2018) and can alter soil physical properties, (de Souza Machado et al., 2018; Qi et al., 2020)). Hence, further studies are encouraged to understand the long-term impacts of this pollution.

\subsection{Microplastic in livestock faeces}

This study provides the first assessment of microplastics in livestock faeces (Fig. 2). Microplastics were found in all the herds. The distribution of microplastics in dry faeces did not follow a normal distribution ( $p$-value $<0.001$ ). The average content of microplastics in dry faeces was $997 \pm 971$ particles $\cdot \mathrm{kg}^{-1}$. We showed that plastics were ingested by sheep grazing on fields where plastic mulch was applied (Fig. 2, herds A, B, C, D) as well as by sheep fed at the sheepfold (Fig. 2, herd E). Shepherds of herds A, B, C and D said that sheep ingested pieces of plastic when they grazed on the vegetable fields. They reported cases of sheep eating macroplastic debris (often plastic mulch or plastic bags) stuck in the vegetation. In fact, we observed a sheep eating a plastic bag while sampling the faeces. The shepherd of herd E, whose sheep did not directly graze on vegetable fields, reported that macroplastic debris was present in the crop residues, in the corn and in the silage that were brought to the animals. He also mentioned that the wind carries macroplastic films (plastic bags, plastic mulch debris, silage sheets debris) to the field where the herd is kept. Sheep ingesting plastic materials have been described in other studies (Ngoshe, 2012; Otsyina et al., 2018) and macroplastics have been found in the digestive systems of the animals (Mekuanint et al., 2017; Omidi et al., 2012). These studies focus on livestock in developing country and identify the free roaming of the animals in the suburbs of cities as the main explanation for plastic ingestion. In our study we observed plastic contamination in the context 
of intensive agriculture, in a rural area. Calcium and phosphorous deficiency and poor nutritional supplementation are predisposing factors for plastic ingestion (Priyanka and Dey, 2018). Overall, we cannot identify a unique source for the microplastics found in the sheep faeces. It is evident that one clear source of microplastic exposure for animals grazing in vegetable fields is the plastic mulch debris left on the fields (herds A, B, C, D). Nevertheless, results from herd E shows that indirect pathways also exist, for example macroplastics transported by the wind to the sheepfold or plastic debris present in the feed. On one hand, microplastics measured in the sheep faeces could have originated from microplastics in the soil or the feed. On the other hand, the microplastics could have also come from ingested macroplastics broken down in the stomachs of the animals. Assessments of the plastic content in the feed and in the environments where the sheep are kept are required to fully understand the contamination pathways.

There was a high variation of microplastic content between faecal samples, from 0 to more than 5000 particles $\cdot \mathrm{kg}^{-1}$. The variation could have come from the uncertainty of the measure caused by a variable amount of organic matter in the faeces or to other factors such as the age of the sheep. In fact, when it comes to sheep accumulating plastic debris, we can expect that the older the sheep is, the more plastic would be found in the faeces. To test this, a better extraction method, with efficient removal of organic matter and a more detailed sampling, classifying the faeces according to the age of the sheep, would be needed.

There are very few assessments of microplastic content in terrestrial animals. Huerta Lwanga et al. (2017b) measured the content of microplastics in the soil $\left(0.87 \pm 1.9\right.$ particles. $\left.{ }^{-1}\right)$, in the earthworms $\left(14.8 \pm 28.8\right.$ particles. $\left.g^{-1}\right)$, and in the chickens $(129.8 \pm 82.3$ particles. $\mathrm{g}^{-1}$ in the faeces and $10.2 \pm 13.8$ particles. $\mathrm{g}^{-1}$ in the gizzard) in traditional Mayan home gardens (Southeast Mexico). The macroplastic content found in the chickens was $45.82 \pm 42.6$ of debris per gizzard and $11 \pm 15.3$ of debris per chicken crop (Huerta Lwanga et al., 2017b). Zhao et al. (2016) identified similar plastic content in 17 wild birds around Shanghai with an average of $22.8 \pm 33.4$ particles per bird. Recently, Yan et al. (2020) detected nylon fibres and polyethylene terephthalate particles of size limit of $\sim 1 \mu \mathrm{m}$ in five out of ten chicken faeces from a farm in Nanjing, China but don't provide quantification. These three studies showed that microplastics can reach terrestrial birds through the food chain, in farms, gardens and in the wild. With our study, we have shown that this concern must be extended to livestock, especially grazing animals.

\subsection{Transport of microplastics}

Sheep from the fields A, B, C and D grazed on crop residues and on fallow lands. By moving from one field to another and to fallow lands sheep can contribute to the transport of microplastics. The calculated transport is an estimation of how many plastic particles are excreted per day by a herd of 1000 sheep grazing on 1 ha. We did not measure the fragmentation rate and residence time of the plastic particles in the digestive systems of the sheep therefore, we could not estimate the ingestion rate based on the plastic content in faeces. We measured a plastic content of $\sim 500$ particles $\cdot \mathrm{kg}^{-1}$ fresh faeces and we could estimate that an average herd of 1000 animals would transport $~ 180,000$ particles.ha ${ }^{-1} \cdot \mathrm{d}^{-1}$. If we assume that one field is grazed 2 times per year, the flux is $\sim 0.36 \times 10^{6}$ particles $\cdot h a^{-1} \cdot y^{-1}$. We can compare this value with two major fluxes of microplastics: sludge application and atmospheric deposition. van den Berg et al. (2020) reported a sludge application of $\sim 20 \mathrm{t} \cdot \mathrm{y}^{-1}$ on cereal agricultural fields in Eastern Spain with a sludge containing $\sim 5000$ particles $\cdot \mathrm{kg}^{-1}$. Therefore, sludge application is an input of $\sim 10^{8}$ particles $\cdot h a^{-1} \cdot y^{-1}$. Zhang et al. (2020) reviewed different studies of atmospheric microplastic transportation and in 17 studies, researchers reported microplastic deposition rates ranging from 0 to 11,130 particles $\cdot \mathrm{m}^{-2} \mathrm{~d}^{-1}$. These studies used different extraction and identification procedures for microplastics, thus making a comparison of the studies complicated. We arbitrarily chose the value of $\sim 60$ particles $\cdot \mathrm{m}^{-2} \mathrm{~d}^{-1}$ reported in the Pyrenees mountains by Allen et al. (2019) because it was the study that was geographically the closest to our case study. We calculated a flux of $\sim 2 \times 10^{8}$ particles $\cdot \mathrm{ha}^{-1} \cdot \mathrm{y}^{-1}$. Therefore, sludge application and atmospheric deposition both represent a microplastic flux 2 orders of magnitude higher than the transport of microplastics in sheep faeces. Quantifying the flux of microplastics is important to be able to predict the amount of microplastics in the environment and determine effective actions to protect ecosystems. More studies, using a standardized plastic identification protocol, are needed to compare the different fluxes of microplastics.

\subsection{Potential effects of plastic ingestion on livestock}

Until now, only a few studies have been designed to assess the adverse health effects of plastic ingestion on livestock. Among potential effects, ingested macroplastics can cause indigestion, ruminal impaction, recurrent ruminal tympany and intestinal obstruction (Kühn and van Franeker, 2020; Mekuanint et al., 2017; Priyanka and Dey, 2018). The fragmentation of the debris in the digestive system could increase the number of small particles, which are then more likely to be absorbed. Plastic debris may also loosely sorb toxic chemicals during degradation (Hüffer et al., 2019) such as the heavy metals and plasticizers used in manufacturing or other contaminants. Plastics sorb many organic pollutants including pesticides (Liu et al., 2019). These chemicals can then contaminate other tissues. For example, Mahadappa et al. (2020) observed increased level of heavy metals in rumen fluid as well as in blood, liver, kidney and muscle of buffaloes that ingested macroplastics. Prata et al. (2020) listed oxidative stress, inflammation, translocation and cancer as potential adverse human health effects caused by microplastics. Additionally, the plastic debris could possibly modify the gut microbiome and alter digestive functions (Fackelmann and Sommer, 2019). Studies investigating the consequences of plastic ingestion are urgently needed.

\subsection{Limitations of the plastic extraction and identification method}

The extraction method successfully identified plastic particles and gave an order of magnitude to the content of plastic in soil and in sheep faeces. The method was fast and inexpensive to implement for both soil and faecal samples. Blanks showed no contamination of the samples during processing. The potential fragmentation of plastic debris during the extraction procedure was not assessed since it was not expected, as reported in previous studies (Corradini et al., 2019b). Zhang et al. (2018) reported a recovery percentage of $>80 \%$ for microplastic identification in soil samples. However, for some faecal samples, the high content of organic matter may have hidden some plastic particles and made the recovery of all the plastic particles impossible (Fig. 3).

Overall, we can expect the number of particles in faecal samples to be under-estimated because of the superposition. Pre-treatments to decrease or remove the organic matter are needed to better quantify the plastic particles. A diversity of methods have been tested to extract microplastic from complex environmental samples (soil or faeces) and rely on the diversity of plastic properties (Möller et al., 2020). The density separation methods, similar to the one we used, require an additional step to limit the organic material fraction to an appropriate level. Acidic and Alkaline Digestion, Oxidisation with Hydrogen Peroxide or Enzymatic Digestion can be used and combined to reduce the organic material fraction. For example, Yan et al. (2020), obtained more than $90 \%$ recovery for polystyrene, polyethylene and polyvinyl chloride microplastics extracted from human and chicken faeces with a density separation with ethyl alcohol and the use Fenton's reagent and nitric acid. Other methods such as the magnetic (Grbic et al., 2019), electrochemistry (Davies and Crooks, 2020) and oil extraction (Scopetani et al., 2020) seems to better separate certain plastic types from organic materials. All these methods have to be adapted to the matrix and 

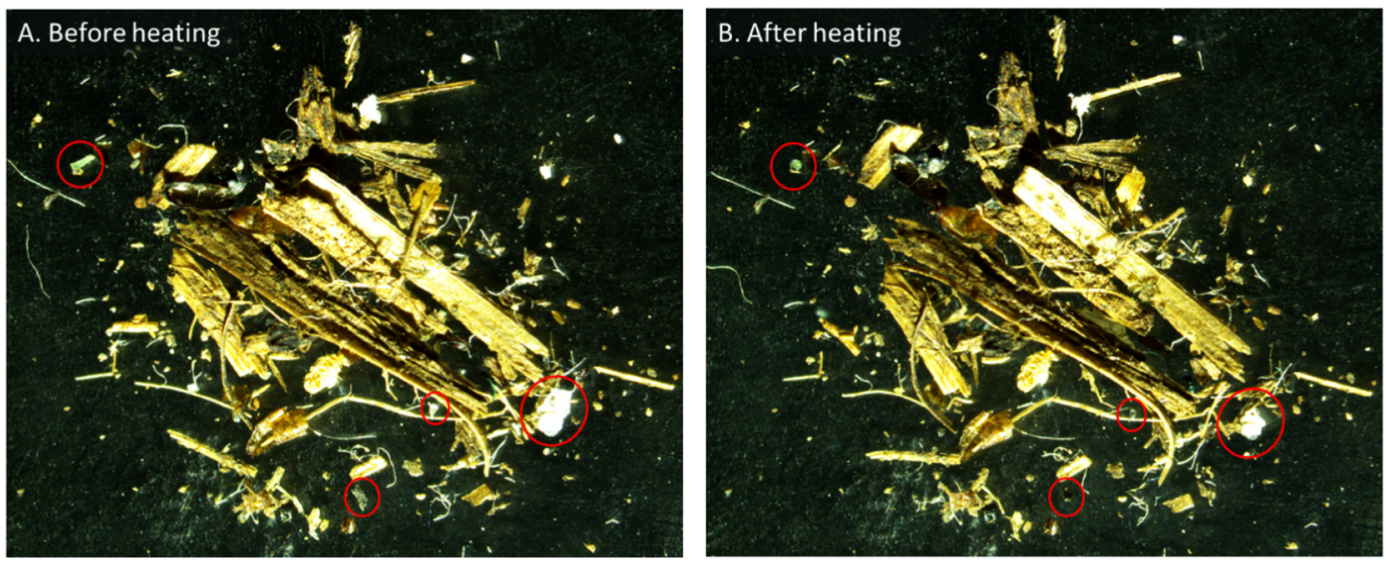

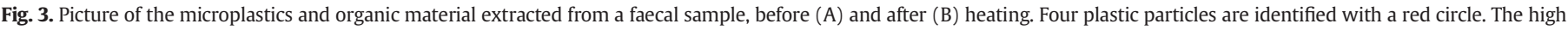
amount of organic matter present in the picture does not allow for a complete assessment of the sample.

plastic type analysed and require internal recovery tests to ensure the proper extraction of the plastic materials.

The visual identification has been validated in numerous studies (Möller et al., 2020). However it does not differentiate the type of plastic and is less suitable for particles with a diameter smaller than $50 \mu \mathrm{m}$ (Zhang et al., 2018). Spectral methods (e.g. Raman or Fourier transform infrared) are used to identify several types of plastic by comparison with a spectral library (Corradini et al., 2019a; Munno et al., 2020; Sobhani et al., 2019). Raman microspectroscopy allows microplastic identification down to a pixel resolution of $500 \mathrm{~nm}$ and could be improved up to $100 \mathrm{~nm}$ with silver colloid for surface-enhanced Raman spectroscopy (Lv et al., 2020) while micro-FTIR spectroscopy identification of particles ranges from 10 to $500 \mu \mathrm{m}$ (Möller et al., 2020). The identification of nanoplastics remains a challenge and new methods have to be validated in environmental samples.

\section{Conclusions}

This study reported the first measured content of light density microplastics in sheep faeces $\left(\sim 10^{3}\right.$ particles $\left.\cdot \mathrm{kg}^{-1}\right)$. We demonstrated that livestock could ingest micro- and/or macro-plastic debris from their environment and from their feed. The light density microplastic content in the vegetables fields was $\sim 2 \times 10^{3}$ particles $\cdot \mathrm{kg}^{-1}$. We identified agricultural plastics as one but not the unique source of plastic contamination. This preliminary study emphasizes the need for standardized methods for measuring plastic content, assessments of the effects of plastic debris ingested by livestock, identification of the source of plastics ingested by livestock and proposals for alternatives to the plastics used in agriculture. The plastic contamination, from intensive agriculture management and other sources, is a threat to the fauna and humans. With the intensification of agriculture we can expect an increase of plastic use leading to an increase plastic contamination and exposure. A paradigm shift is needed in the current crop production to reverse this trend.

\section{CRediT authorship contribution statement}

Nicolas Beriot: Conceptualization, Investigation, Formal analysis, Methodology, Writing - original draft, Writing - review \& editing.

Joost Peek: Conceptualization, Investigation, Formal analysis, Methodology, Writing - original draft.

Esperanza Huerta Lwanga: Conceptualization, Investigation, Resources, Methodology, Supervision, Writing - review \& editing.

Raul Zornoza: Resources, Funding acquisition, Project administration, Writing - review \& editing.
Violette Geissen: Resources, Funding acquisition, Project administration, Writing - review \& editing.

\section{Declaration of competing interest}

The authors declare that they have no known competing financial interests or personal relationships that could have appeared to influence the work reported in this paper.

\section{Acknowledgement}

This work was supported by the European Commission Horizon 2020 project Diverfarming [grant agreement 728003]. We are thankful for the contribution of the farmers and sheepherders from the region of Murcia, Spain. We would also like to thank Robin Palmer for the language editing.

\section{References}

Agudo, B., L., F., Lavín, Paz, Mantecón, Ángel R., 2010. Farm Management of Sheep Farms in Extremadura: Effect of Flock Size. Sociedad Española de Ovinotecnia y Caprinotecnia, Digital.CSIC.

Allen, S., Allen, D., Phoenix, V.R., Le Roux, G., Durántez Jiménez, P., Simonneau, A., Binet, S., Galop, D., 2019. Atmospheric transport and deposition of microplastics in a remote mountain catchment. Nat. Geosci. 12 (5), 339-344.

Bläsing, M., Amelung, W., 2018. Plastics in soil: analytical methods and possible sources. Sci. Total Environ. 612, 422-435.

Chae, Y., An, Y.-J., 2020. Nanoplastic Ingestion Induces Behavioral Disorders in Terrestrial Snails: Trophic Transfer Effects Via Vascular Plants. Nano, Environmental Science.

Corradini, F., Bartholomeus, H., Huerta Lwanga, E., Gertsen, H., Geissen, V., 2019a. Predicting soil microplastic concentration using vis-NIR spectroscopy. Sci. Total Environ. 650, 922-932.

Corradini, F., Meza, P., Eguiluz, R., Casado, F., Huerta-Lwanga, E., Geissen, V., 2019b. Evidence of microplastic accumulation in agricultural soils from sewage sludge disposal. Sci. Total Environ. 671, 411-420.

Crawford, C.B., Quinn, B., Crawford, C.B., Quinn, B., 2017. Microplastic Pollutants. Elsevier, pp. $57-100$.

Davies, C.D., Crooks, R.M., 2020. Focusing, sorting, and separating microplastics by serial faradaic ion concentration polarization. Chem. Sci. 11 (21), 5547-5558.

de Souza Machado, A.A., Lau, C.W., Till, J., Kloas, W., Lehmann, A., Becker, R., Rillig, M.C., 2018. Impacts of microplastics on the soil biophysical environment. Environ. Sci. Technol. 52 (17), 9656-9665.

Dirección General de Producciones y Mercados Agrarios, 2020. In: Ministerio de Agricultura, Pesca y Alimentación (Ed.), El sector Ovino y caprino de carne en cifras. Catálogo de Publicaciones de la Administración General del Estado, NIPO: 003191420 https:/www.mapa.gob.es/es/ganaderia/temas/produccion-y-mercadosganaderos/indicadoreseconomicosdelsectorovinoycaprino_carne_tcm305114962019_tcm30-511496.pdf. (Accessed June 2020).

Fackelmann, G., Sommer, S., 2019. Microplastics and the gut microbiome: how chronically exposed species may suffer from gut dysbiosis. Mar. Pollut. Bull. 143, 193-203.

Grbic, J., Nguyen, B., Guo, E., You, J.B., Sinton, D., Rochman, C.M., 2019. Magnetic extraction of microplastics from environmental samples. Environmental Science \& Technology Letters 6 (2), 68-72. 
Horton, A.A., Dixon, S.J., 2018. Microplastics: an introduction to environmental transport processes. WIREs Water 5 (2), e1268.

Huerta Lwanga, E., Gertsen, H., Gooren, H., Peters, P., Salánki, T., van der Ploeg, M., Besseling, E., Koelmans, A.A., Geissen, V., 2017a. Incorporation of microplastics from litter into burrows of Lumbricus terrestris. Environ. Pollut. 220, 523-531.

Huerta Lwanga, E., Mendoza Vega, J., Ku Quej, V., Chi, J.d.l.A., Sanchez del Cid, L., Chi, C., Escalona Segura, G., Gertsen, H., Salánki, T., van der Ploeg, M., Koelmans, A.A., Geissen, V., 2017b. Field evidence for transfer of plastic debris along a terrestrial food chain. Sci. Rep. 7 (1), 14071.

Hüffer, T., Metzelder, F., Sigmund, G., Slawek, S., Schmidt, T.C., Hofmann, T., 2019. Polyethylene microplastics influence the transport of organic contaminants in soil. Sci. Total Environ. 657, 242-247.

Huston, J., Rector, B., Ellis, W., Allen, M., 1986. Dynamics of digestion in cattle, sheep, goats and deer. J. Anim. Sci. 62, 208-215.

Kühn, S., van Franeker, J.A., 2020. Quantitative overview of marine debris ingested by marine megafauna. Mar. Pollut. Bull. 151, 110858.

Liu, E.K., He, W.Q., Yan, C.R., 2014. 'White revolution' to ‘white pollution'-agricultural plastic film mulch in China. Environ. Res. Lett. 9 (9), 091001.

Liu, G., Zhu, Z., Yang, Y., Sun, Y., Yu, F., Ma, J., 2019. Sorption behavior and mechanism of hydrophilic organic chemicals to virgin and aged microplastics in freshwater and seawater. Environ. Pollut. 246, 26-33.

Lv, L., He, L., Jiang, S., Chen, J., Zhou, C., Qu, J., Lu, Y., Hong, P., Sun, S., Li, C., 2020. In situ surface-enhanced Raman spectroscopy for detecting microplastics and nanoplastics in aquatic environments. Sci. Total Environ. 728, 138449.

Mahadappa, P., Krishnaswamy, N., Karunanidhi, M., Bhanuprakash, A.G., Bindhuja, B.V., Dey, S., 2020. Effect of plastic foreign body impaction on rumen function and heavy metal concentrations in various body fluids and tissues of buffaloes. Ecotoxicol. Environ. Saf. 189, 109972.

Mekuanint, S., Alemneh, T., Asredie, T., 2017. Indigestible rumen foreign bodies cause of rumen impaction in cattle, sheep and goats slaughtered at Addis Ababa Abattoir Enterprise, Ethiopia. Journal of Veterinary Science and Medicine 5 (1), 5.

Möller, J.N., Löder, M.G.J., Laforsch, C., 2020. Finding microplastics in soils: a review of analytical methods. Environ. Sci. Technol. 54 (4), 2078-2090.

Munno, K., De Frond, H., O'Donnell, B., Rochman, C.M., 2020. Increasing the accessibility for characterizing microplastics: introducing new application-based and spectral libraries of plastic particles (SLoPP and SLoPP-E). Anal. Chem. 92 (3), 2443-2451.

Ngoshe, A., 2012. Incidence of polythene bag ingestion by ruminant animals at Maiduguri Central Abattoir. Ramat J. Manag. Sci. Technol. 1, 12-16.

Ogejo, J., Wildeus, S., Knight, P., Wilke, R., 2010. Technical note: estimating goat and sheep manure production and their nutrient contribution in the Chesapeake Bay Watershed. Appl. Eng. Agric. 26, 1061-1065.

Omidi, A., Naeemipoor, H., Hosseini, M., 2012. Plastic debris in the digestive tract of sheep and goats: an increasing environmental contamination in Birjand, Iran. Bull. Environ. Contam. Toxicol. 88 (5), 691-694.

Otsyina, H.R., Nguhiu-Mwangi, J., Mogoa, E.G.M., Mbuthia, P.G., Ogara, W.O., 2018. Knowledge, attitude, and practices on usage, disposal, and effect of plastic bags on sheep and goats. Trop. Anim. Health Prod. 50 (5), 997-1003.

Prata, J.C., da Costa, J.P., Lopes, I., Duarte, A.C., Rocha-Santos, T., 2020. Environmental exposure to microplastics: an overview on possible human health effects. Sci. Total Environ. $702,134455$.

Priyanka, M., Dey, S., 2018. Ruminal impaction due to plastic materials - An increasing threat to ruminants and its impact on human health in developing countries. Veterinary World 11 (9), 1307-1315.
Qi, Y., Yang, X., Pelaez, A.M., Huerta Lwanga, E., Beriot, N., Gertsen, H., Garbeva, P., Geissen, V., 2018. Macro- and micro-plastics in soil-plant system: effects of plastic mulch film residues on wheat (Triticum aestivum) growth. Sci. Total Environ. 645, 1048-1056.

Qi, Y., Beriot, N., Gort, G., Huerta Lwanga, E., Gooren, H., Yang, X., Geissen, V., 2020. Impact of plastic mulch film debris on soil physicochemical and hydrological properties. Environ. Pollut. 266, 115097.

Rakkar, M.K., Blanco-Canqui, H., 2018. Grazing of crop residues: impacts on soils and crop production. Agric. Ecosyst. Environ. 258, 71-90.

Rillig, M.C., Ingraffia, R., de Souza Machado, A.A., 2017. Microplastic incorporation into soil in agroecosystems. Front. Plant Sci. 8 (1805).

Schwabl, P., Köppel, S., Königshofer, P., Bucsics, T., Trauner, M., Reiberger, T., Liebmann, B. 2019. Detection of various microplastics in human stool: a prospective case series. Ann. Intern. Med. 171.

Scopetani, C., Chelazzi, D., Mikola, J., Leiniö, V., Heikkinen, R., Cincinelli, A., Pellinen, J. 2020. Olive oil-based method for the extraction, quantification and identification of microplastics in soil and compost samples. Sci. Total Environ. 733 (139338).

Sobhani, Z., Al Amin, M., Naidu, R., Megharaj, M., Fang, C., 2019. Identification and visualisation of microplastics by Raman mapping. Anal. Chim. Acta 1077, 191-199.

Taylor, J.A., Robinson, G.G., Hedges, D.A., Whalley, R.D.B., 1987. Camping and faeces distribution by Merino sheep. Appl. Anim. Behav. Sci. 17 (3), 273-288.

van den Berg, P., Huerta-Lwanga, E., Corradini, F., Geissen, V., 2020. Sewage sludge application as a vehicle for microplastics in eastern Spanish agricultural soils. Environ. Pollut. 261, 114198.

Wang, W., Gao, H., Jin, S., Li, R., Na, G., 2019. The ecotoxicological effects of microplastics on aquatic food web, from primary producer to human: A review. Ecotoxicol. Environ. Saf. 173, 110-117.

Weithmann, N., Möller, J.N., Löder, M.G.J., Piehl, S., Laforsch, C., Freitag, R., 2018. Organic fertilizer as a vehicle for the entry of microplastic into the environment. Sci. Adv. 4 (4) (eaap8060).

Wu, P., Huang, J., Zheng, Y., Yang Y., Zhang, Y., He, F., Chen, H., Quan, G., Yan, J., Li, T., Gao, B., 2019. Environmental occurrences, fate, and impacts of microplastics. Ecotoxicol. Environ. Saf. 184, 109612.

Xu, B., Liu, F., Cryder, Z., Huang, D., Lu, Z., He, Y., Wang, H., Lu, Z., Brookes, P.C., Tang, C. Gan, J., Xu, J., 2020. Microplastics in the soil environment: occurrence, risks, interactions and fate - a review. Crit. Rev. Environ. Sci. Technol. 50 (21), 2175-2222.

Yan, Z., Zhao, H., Zhao, Y., Zhu, Q., Qiao, R., Ren, H., Zhang, Y., 2020. An efficient method for extracting microplastics from feces of different species. J. Hazard. Mater. 384, 121489

Yang, X., Guo, X., Huang, S., Xue, S., Meng, F., Qi, Y., Cheng, W., Fan, T., Lwanga, E.H., Geissen, V., 2020. In: He, D., Luo, Y. (Eds.), Microplastics in Terrestrial Environments: Emerging Contaminants and Major Challenges. Springer International Publishing, Cham, pp. 245-258.

Zhang, G.S., Liu, Y.F., 2018. The distribution of microplastics in soil aggregate fractions in southwestern China. Sci. Total Environ. 642, 12-20.

Zhang, S., Yang, X., Gertsen, H., Peters, P., Salánki, T., Geissen, V., 2018. A simple method for the extraction and identification of light density microplastics from soil. Sci. Total Environ. 616-617, 1056-1065.

Zhang, Y., Kang, S., Allen, S., Allen, D., Gao, T., Sillanpää, M., 2020. Atmospheric microplastics: a review on current status and perspectives. Earth Sci. Rev. 203, 103118.

Zhao, S., Zhu, L., Li, D., 2016. Microscopic anthropogenic litter in terrestrial birds from Shanghai, China: not only plastics but also natural fibers. Sci. Total Environ. 550, 1110-1115. 